\title{
Structural properties of a new material made of waste paper
}

\author{
J. Santamaria ${ }^{1}$, B. Fuller ${ }^{2} \&$ A. Fafitis ${ }^{1}$ \\ ${ }^{I}$ Department of Civil and Environmental Engineering, \\ Arizona State University, USA \\ ${ }^{2}$ Center for Alternative Building Studies, USA
}

\begin{abstract}
Papercrete is the name of a new construction material made basically of waste paper, cement and water. Contractors have started using papercrete to build low cost houses relying on empirical knowledge of its structural properties. The purpose of this study is to obtain some mechanical and physical parameters of papercrete by doing several laboratory tests. The samples tested were made following the most common procedures that papercrete makers are currently using. The experimental setup used to test the samples is briefly described and some test results are presented. Some conclusions and recommendations for the use of papercrete for building houses are also presented.

Keywords: waste paper, recycling, sustainability, low-cost housing, greenconstruction.
\end{abstract}

\section{Introduction}

The necessity of low-cost housing has pushed people to look for alternative construction materials. "Papercrete" is a relatively new material basically made of waste paper, cement, and water. Papercrete is a slightly misleading name. It seems to imply a mix of paper and concrete, hence papercrete. But more accurately, only the Portland cement part of concrete is used in the mix - along with other admixtures. Although some sand and other additives to improve its behavior under compressive load may be used, the basic components are still the same.

According to the Environmental Protection Agency (EPA), the United States recycles about $45 \%$ of discarded paper annually, U.S. EPA, 2000 [10]. This 
means that about $55 \%$ or 48 million tons of paper is thrown away or goes into the landfills. Conservatively speaking, it takes about fifteen trees to make a ton of paper. That means that 720 million trees are used once and then buried in a landfill each year. The volume of the paper material wasted every year is equivalent to the volume of a wall 48 feet high and 1 foot wide, around the entire perimeter of the United States, Fig. 1.

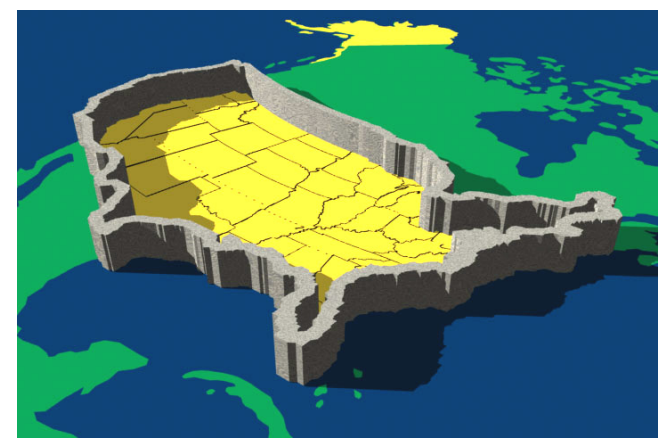

Figure 1: $\quad$ Waste paper wall around the U.S.A. made of waste paper.

At the same time, in Arizona and many other states, there is a pressing need for affordable, sustainable housing. On Native American lands in Arizona alone, there is an immediate and pressing need for tens of thousands of homes. According to a report by the Arizona Housing Commission, "The urgent overriding message is clear; housing affordability is an impending crisis in Arizona", Arizona Housing Commission, 2000 [1].

The research and testing on papercrete is very limited or nonexistent. From a scientific standpoint papercrete is, for all practical purposes, invisible. To the best of our knowledge there is no systematic experimental or analytical study of this material. So there are few ways to reference papercrete because there are no antecedents in research - only locations, structures and people who have built them. Some parallel work has been done on fiber cement composites for roofing and siding, Mohr et al. 2004 [5], but to our knowledge, no formal research.

The purpose of this research is to determine if papercrete has suitable mechanical and physical properties so that it can be used as a construction material for houses, to find out what anecdotal evidence about it is accurate, and to determine areas of further study, if any. The parameters to be studied are the Young's Modulus (E), thermal conductivity $(\mathrm{K})$, thermal resistance $(\mathrm{R})$, bond characteristics, and creep behavior.

\section{Anecdotal evidence}

As part of the search for anecdotal evidence several papercrete structures were visited and practitioners were interviewed. It was found that the locations of the structures represent a cross-section of climate and geography. Many of these structures are standing for years and they are quite attractive, Fig. 2. 


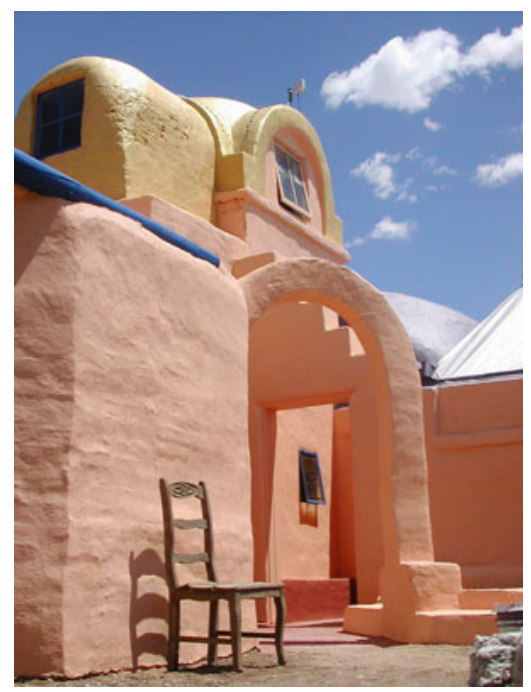

Figure 2: Papercrete structures are attractive, and said to have a number of positive properties.

Homes and other buildings of up to 3200 square feet have been built with papercrete for $\$ 25$ per square foot, not including labor. Finished designer homes made of papercrete have cost $\$ 70-\$ 80$ per square foot, with labor included. There seems to be no harmful by-products or excessive use of energy in the production of papercrete, Hart 2004 [3]. Current mixes can be produced using electric motors powered by solar energy, McCain 2004 [4]. Since the mortar, exterior stucco and interior plaster used with papercrete is made of the same paper material, much wood and other construction materials used in framing and "building out" the interior and exterior of the home is saved. With an R-Value between 2.0 and 3.0 per inch, U.S. DOE 2002 [9], in walls 12 to16 inches thick, the long-term energy savings of buildings with papercrete is considerable for the homeowner and the environment.

Papercrete is reported to have good sound absorption quality. It's also reported to be flame and fungus retardant, as well as bug, rodent and pest resistant, Patterson 2004 [6]. Since it is very light, it would be an ideal interior wall material for high-rise buildings in active seismic areas. Using it in place of concrete would reduce the gauge of steel framework and the depth of foundations - cutting materials, labor and energy costs significantly.

Papercrete wall and roof material is, in itself, insulation. It surrounds, supports and insulates the structure's climate control, plumbing, and electrical systems. Communication, security, fire, moisture and structural stress monitors can be run between courses of the material during construction or cut into the walls after completion, Terry 2004 [7].

Vaults and domes made of papercrete have been built, Fig. 3, on walls with no reinforcement of any kind, Curry 2004 [2]. Due to the fact that it is so lightweight and easy to install, labor cost is reduced. 


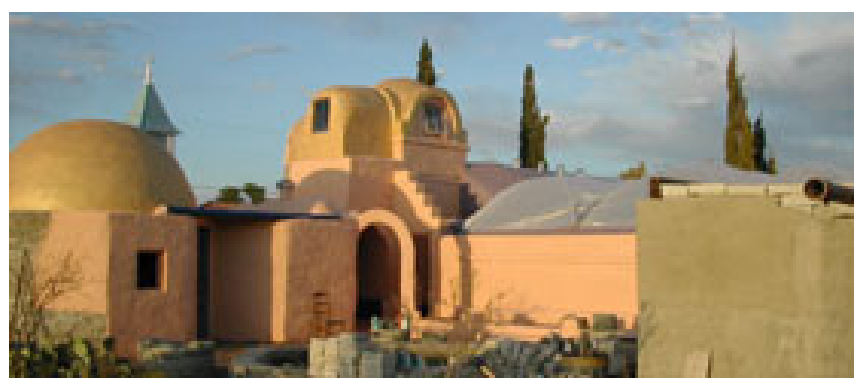

Figure 3: Papercrete domes and vaults built without interior reinforcement.

Experimental structures, which are still standing, have been built without footings, directly on the ground and on sand bags, McCain 2004 [4].

Others have been built more conventionally on piers and on concrete footings and slabs, Terry 2004 [7]. Walls have been dry stacked, pinned with rebar, and poured in forms on the ground and then tipped up. They also have been poured monolithically, slip formed or used as infill in post and beam construction with a wood or steel framework, McCain 2004 [4].

Papercrete blocks made with sufficient Portland cement are fire retardant. They will not burn with an open flame. The blocks can be made waterproof by using a concrete sealer. In rural communities, with no current recycling services, making papercrete blocks increases the recycling of waste paper and creates new rural jobs and economic opportunities Fig. 4). Small communities, with even a modest waste paper stream, can start a cottage industry based on this material and save waste transportation fees to regional landfills.

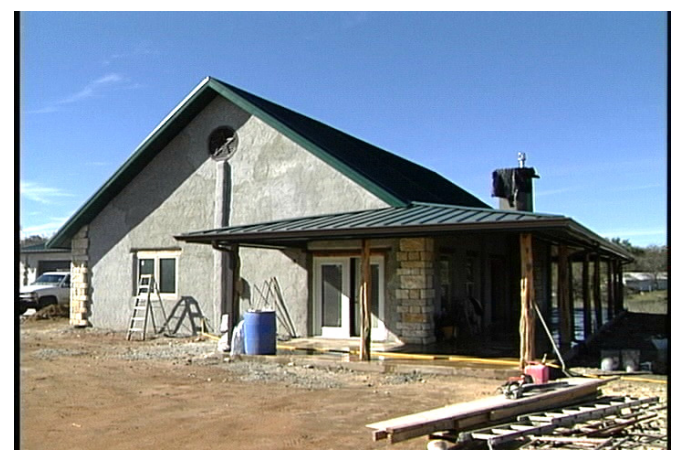

Figure 4: $\quad$ Papercrete house built in a small community.

The economic bonus is that there is no waste. Sawdust, cuttings, spills and broken pieces can be returned to the mixer for re-use, McCain 2004 [4]. The environmental bonus is that there is a sizable savings in trees and landfill space, new uses for other waste materials such as glass, fly ash and Styrofoam, and an estimated $50 \%$ to $70 \%$ savings in energy to heat and cool a papercrete home during its lifetime. 


\section{Experimental program}

\subsection{Compressive test}

In theses tests an increasing uniaxial compressive load was applied at constant speed, uniformly distributed in order to develop the stress-strain curve and determine the stiffness of the material. The following testing procedure was used for the compression test:

Since some samples had irregular faces, they were made flat by using normal commercial mortar cap. The samples were tested under uniaxial compressive force using a 100ton-compression machine, Fig. 5. The loading rate at the displacement control mode was $0.35 \mathrm{in} / \mathrm{min}$, and all samples were loaded up to approximately $10 \mathrm{kips}$, unloaded, and reloaded to approximately 15 kips.

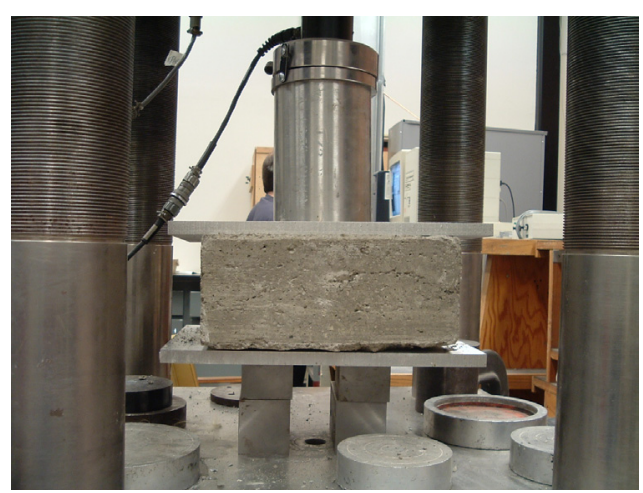

Figure 5: Compression test.

Failure was defined by deformation criteria rather than load because the material is not brittle, and it does not exhibit descending branch in the stressstrain curve. It was found that at 15 kips the deformation was excessive, rendering the material useless.

\subsection{Pull-out test}

The purpose of this test was to measure the bond capacity of a material by applying an increasing force to extract a corrugated steel bar that was previously driven. The following testing procedure was used for the Pull-Out Test: The samples were prepared by driving the rebar in the middle of a block of Papercrete. Two different kinds of samples were tested. The sample is subjected to an increasing load in order to pull out the steel bar. The loading rate at the displacement control mode was $0.35 \mathrm{in} / \mathrm{min}$. In the same way as the compression test, failure was defined by deformation criteria. 


\subsection{Creep test}

The purpose of this test was to study the behavior of the material when it is subjected to a constant compressive load for a long period of time. The following testing procedure was used for the Creep Test:

All creep samples were made by cutting papercrete blocks of approximately 3 in $\mathrm{x} 3$ in $\mathrm{x} 9$ in. The axial deformations were measured by a mechanical gage.

Each sample was subjected to a constant load of approximately $300 \mathrm{lb}$ for a period of time of four weeks approximately. It was found that practically all creep had taken place within approximately three weeks. The deformation was measured with 0.001 in. accuracy.

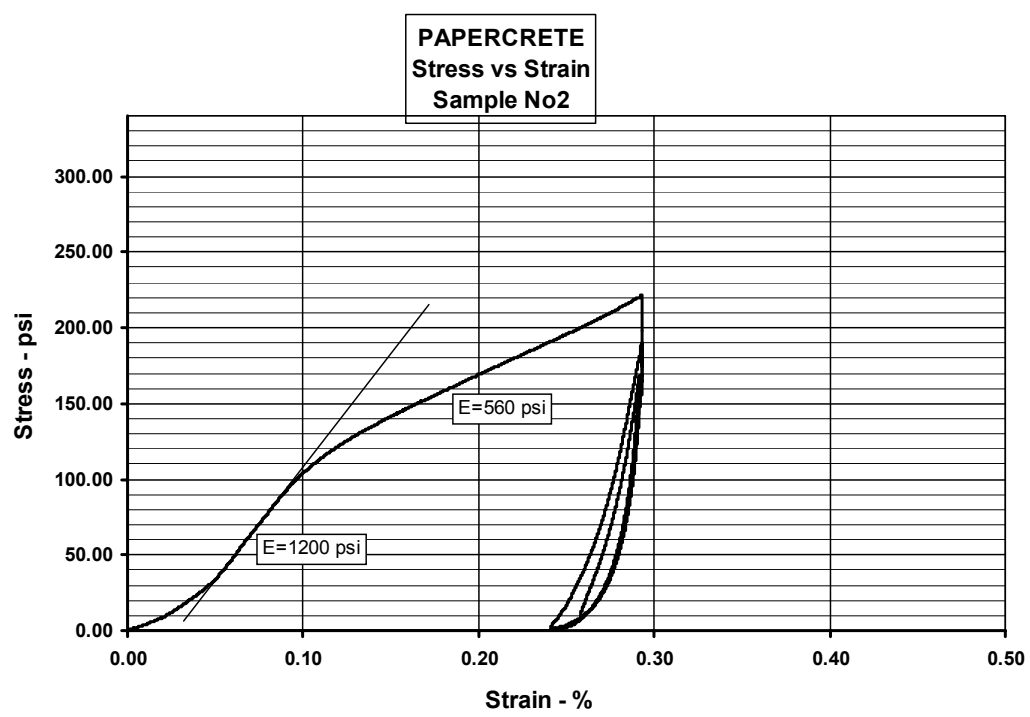

Figure 6: Stress vs. Strain graph.

\section{Test results and analysis}

\subsection{Compressive tests}

The data collected from the compression tests were used to develop stress-strain curves for each sample. The stiffness or elastic modulus of the material (E) is the slope of the stress-strain curve. A trend line was obtained using Microsoft Excel in order to get the right value of the slope of the curve, Fig. 6 . Note that the material is non-linear, and as a result there is no Elastic (Young's) Modulus. A working Young's Modulus is an approximate value obtained from the stressstrain curves, and which can be used as an index to characterize the compressive behavior up to some stress. In practice, the allowable compressive stress is 
expected to be at about this level. The softer part of the curve, Fig. 6, is probably due to irregularities of the surfaces of the specimens. The compressive test results of all samples are shown in Table 1.

\subsection{Pull-out tests}

The data collected from five pull-out tests were used to develop a Load vs. Deformation graph for each sample. A typical force-deformation curve is shown in Fig.7. The maximum pull-out force for each specimen is given in Table 2.

Table 1: $\quad$ Papercrete compressive tests.

\begin{tabular}{|c|c|c|c|c|}
\hline Group & Sample & Material & Proportions & Elastic Modulus \\
\hline 1 & 1 & Paper/Portland & $1-1$ & 600 \\
\hline 1 & 2 & Paper/Portland & $1-2$ & 1200 \\
\hline 1 & 3 & Paper/Portland & $1-3$ & 2000 \\
\hline 2 & 4 & Paper/Port/Sand & $1-1-5 \mathrm{gal}$ & 800 \\
\hline 2 & 5 & Paper/Port/Sand & 1-1-10gal & 700 \\
\hline 2 & 6 & Paper/Port/Sand & $1-1-15 \mathrm{gal}$ & 590 \\
\hline 3 & 7 & Paper/Port/Fly ash & $1-.7-.25$ & 950 \\
\hline 3 & 8 & Paper/Port/Fly ash & $1-.6-.30$ & 420 \\
\hline 3 & 9 & Paper/Port/Fly ash & $1-.5-.35$ & 400 \\
\hline 4 & 13 & Paper/Port/Styrofoam & $15 \%$ Sty & 1200 \\
\hline 4 & 14 & Paper/Port/Styrofoam & $20 \%$ Sty & 1430 \\
\hline 4 & 15 & Paper/Port/Styrofoam & $25 \%$ Sty & 860 \\
\hline 5 & 16 & Sludge/Port/Fly & $1-.7-.25$ & 1390 \\
\hline 5 & $17-18$ & Sludge/Port/Fly & $1-.6-.30$ & 2700 \\
\hline 6 & 19 & Paper/Port/Glass & $1-1-5$ gal & 470 \\
\hline 6 & 20 & Paper/Port/Glass & $1-1-10 \mathrm{gal}$ & 570 \\
\hline 6 & 21 & Paper/Port/Glass & $1-1-15 \mathrm{gal}$ & 700 \\
\hline 7 & 22 & Paper/Clay & $0 \%$ Portland & 1394 \\
\hline 8 & 23 & Paper/Port/Clay & 1 bag mix & 855 \\
\hline 8 & 24 & Paper/Port/Clay & 2 bag mix & 1375 \\
\hline 9 & 25 & Paper/Port/Lime & $1-.5-.5$ & 400 \\
\hline 9 & 26 & Paper/Port/Lime & $1-1-1$ & 570 \\
\hline 9 & 27 & Paper/Port/Lime & $1-1.5-1.5$ & 660 \\
\hline 10 & 30 & $1 / 8$ inch grind & $1-2$ & 1550 \\
\hline 10 & 33 & $3 / 8$ inch grind & $1-2$ & 2000 \\
\hline 10 & 35 & $5 / 8$ inch grind & $1-2$ & 1200 \\
\hline 11 & 36 & Clyde T. Curry: Poured 2/13/05 & Per yard & 1250 \\
\hline 12 & 37 & Zach Rabon: Poured 2/05/05 & Per yard & 3000 \\
\hline 13 & 60 & Cardboard Pour 3/17/05 & .7 per yard & 220 \\
\hline 14 & 38 & Paper/Port/Fly ash/Sand & 200 gal & 1200 \\
\hline 14 & 39 & Paper/Port/Fly ash/Sand & $200 \mathrm{gal}$ & 900 \\
\hline 15 & 40 & SRP Printing Paper & 0.70 & 1500 \\
\hline 16 & 41 & Mixed Waste Paper & $1 / 2$ batch & 1300 \\
\hline 17 & 42 & Paper/Port/Fly Ash/Sand & 0.70 & 2100 \\
\hline
\end{tabular}

\subsection{Creep tests}

The data collected from the creep test were used to develop a Deformation vs. Time graph for each sample. Atypical curve is shown in Fig. 8. It is apparent that the deformation (creep) behavior under a constant load tends quickly to an 
asymptote. To smoothen the curve, a trend line was applied using Microsoft Excel. Six samples were tested for creep and the results are tabulated in Table 3. Samples No2 and No4 were made using the corresponding mixtures in Table 1.

\section{Conclusions and recommendations}

Papercrete has wide-ranging implications for home construction and the environment. The challenge of papercrete is the lack of information about it. More research is needed in order to learn more about the material and to its properties. The results of this study indicate that papercrete, properly mixed and applied, should be safe and practical for two-story residential home construction.

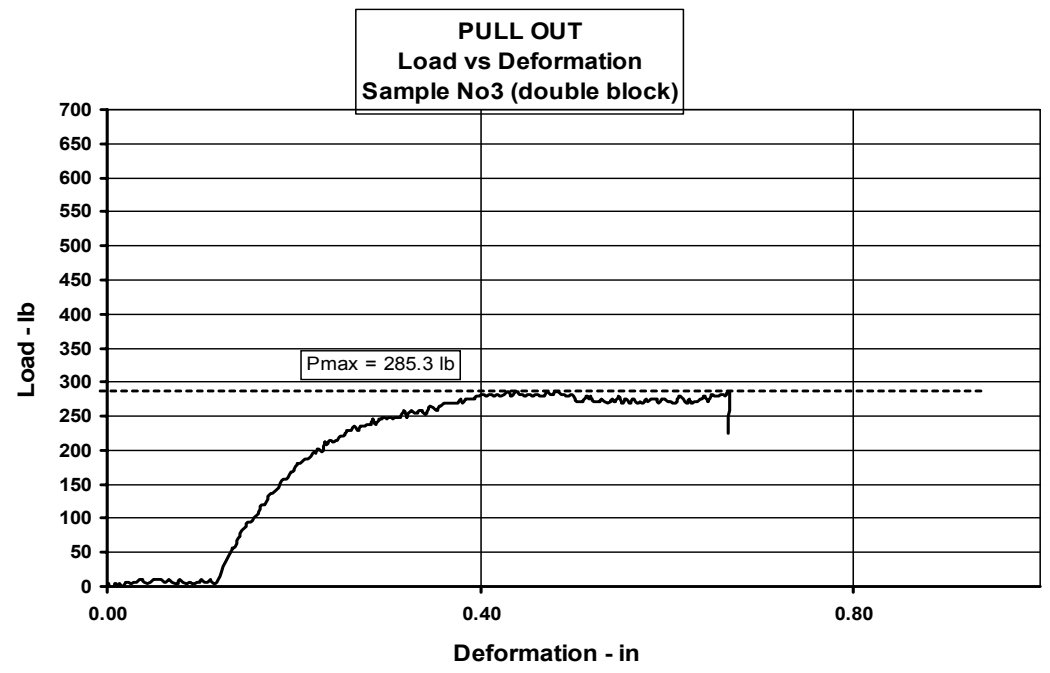

Figure 7: Load - deformation.

Table 2: $\quad$ Pull out tests.

\begin{tabular}{llll}
\hline Group & Sample & Type & $\begin{array}{l}\text { Pmax } \\
(\mathbf{l b})\end{array}$ \\
\hline 1 & 1 & Single & 60.4 \\
1 & 2 & Single & 47.0 \\
2 & 3 & Double & 285.0 \\
2 & 4 & Double & 130.1 \\
2 & 5 & Double & 694.0 \\
\hline
\end{tabular}

\subsection{Compressive test}

When the samples were capped, all of them absorbed a lot of water very quickly. However, no apparent change in the samples after the seven day curing period was observed. During the compression test, the stress-strain curve is 
monotonically increasing and the sample starts packing rather than disintegrating. For that reason, deformation is the criterion for failure. The stressstrain curves suggest that, papercrete is a ductile material that can sustain large deformations. Cement plays an important role in the compressive strength and behavior. Specimens with higher proportion of cement exhibit larger Young's Modulus. As pointed out, the stress-strain curves exhibit a softer segment at the beginning. This is probably because of the inherent irregularities of the specimens due to shrinkage. It is believed that, in practice (for example in the construction of a wall), the self-weight of the structure will apply a moderate pressure which will bring the stress at the level of the working Young's Modulus which can be used in design.

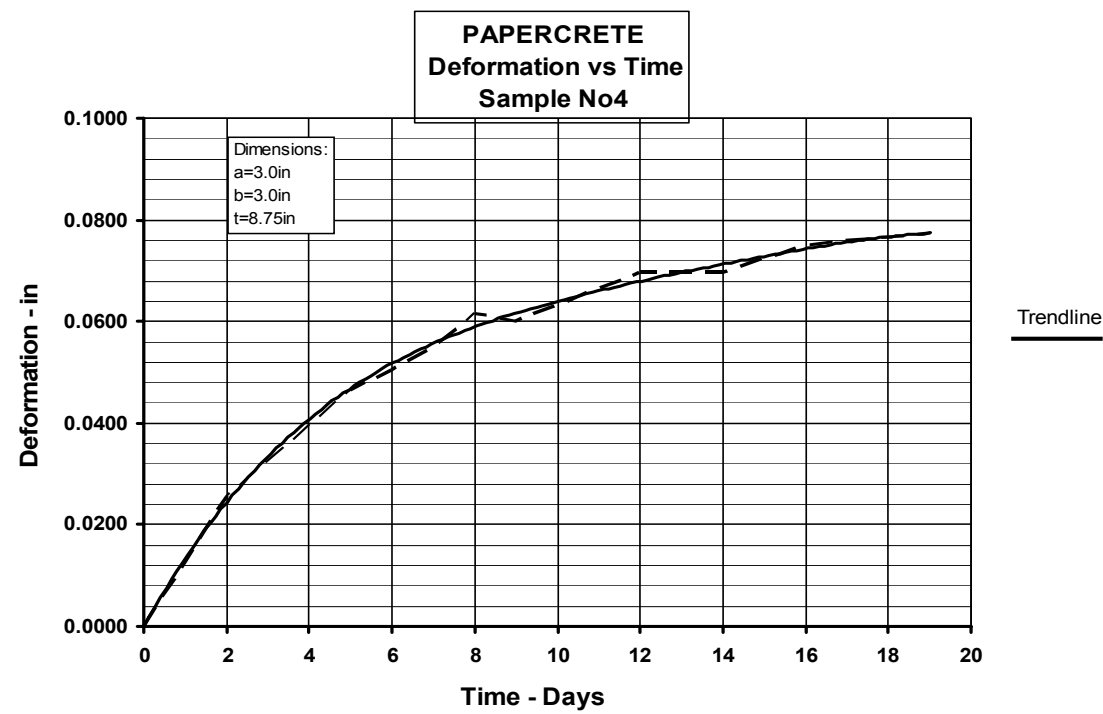

Figure 8: Deformation vs. time curve.

Table 3: $\quad$ Creep test results.

\begin{tabular}{llllll}
\hline Sample & $\begin{array}{l}\text { Contac } \\
\text { Area } \\
\text { No }\end{array}$ & $\begin{array}{l}\text { Load } \\
\text { (in) }\end{array}$ & $\begin{array}{l}\text { Stress } \\
\text { (psi) }\end{array}$ & $\begin{array}{l}\text { Deformation } \\
\text { creep } \\
\text { (inch) }\end{array}$ & \\
\hline 2.1 & 9.0 & 307.5 & 34.17 & 0.0108 & \\
2.2 & 9.0 & 307.5 & 34.17 & 0.0282 & \\
2.3 & 9.0 & 307.5 & 34.17 & 0.0177 & \\
4.1 & 9.0 & 307.5 & 34.17 & 0.0774 & \\
4.2 & 9.0 & 307.5 & 34.17 & 0.0831 & \\
4.3 & 9.0 & 307.5 & 34.17 & 0.0471 & \\
\hline
\end{tabular}




\subsection{Pull out test}

The purpose of this test was to evaluate the pull-out capacity of a driven bar as a fastener. The load-deformation curve is monotonically increasing in a non-linear way until it reaches its maximum. Then it starts decreasing slowly due to the bar wrinkles or folds which prevent the opposite force (friction force) from decreasing drastically. All load-deformation curves exhibit a large number of peaks. This is because the material is broken and packed as the corrugated steel bar is driven by the pulling force. When the material is broken, the pulling load drops, and when the material starts packing, the load increases. The results exhibit considerable scatter. Since the corrugated steel bar was driven into the papercrete blocks by hammering, some factors such as perpendicularity, and packing produced by bar wrinkles or folds may contribute to the scatter.

\subsection{Creep test}

During the creep test, the deformation-time curve is monotonically increasing in a non-linear way until it reaches its maximum. In general, the deformation due to a constant load stopped increasing in less than a month, which is a relative small period of time. It appears that creep depends on the amount of cement, increasing with increasing cement content. However the observed creep was rather small and it does not seem to pose significant structural problems.

\section{References}

[1] Arizona Housing Commission (2000) The State Of Housing in Arizona Retrieved October 6, 2005, from http://www.housingaz.com/UPLOAD/ HsgReprt.pdf

[2] Curry, C. Interview. Living In Paper (work in progress) [Videotape] Dir. Barry J. Fuller Bloomington, New Mexico October 4, 2004

[3] Hart, K. Interview. Living In Paper (work in progress) [Videotape] Dir. Barry J. Fuller Crestone, Colorado June 9, 2004

[4] McCain, M. (producer) (1991) Introduction to Fibercrete [Videotape] (Available from: RV Productions: Albuquerque, New Mexico)

[5] Mohr, B.J., El-Ashkar, N.H., and Kurtis, K.E. (2004) Fiber-cement composites for housing construction: state of the art review. Proceedings of the NSF Housing Research Agenda Workshop, Feb 12-14, 2004, Orlando, Florida. Eds. Syal, M., Hastak, M., and Mullens, M. Vol 2, Focus Group 2, 112-128

[6] Patterson, E. Interview. Living In Paper (work in progress) [Videotape] Dir. Barry J. Fuller Silver City, New Mexico October 2, 2004

[7] Terry, L. Interview. Living In Paper (work in progress) [Videotape] Dir. Barry J. Fuller Columbus, New Mexico June 7, 2004

[8] Thomas, M. Interview. Living In Paper (work in progress) [Videotape] Dir. Barry J. Fuller Navajo Dam, New Mexico April 14, 2004 
[9] U.S. DOE (2002) R-value of papercrete [Email: Arun Vohra to Lex Terry] April 9, 2002

[10] U.S. EPA (2000) Jobs Through Recycling Retrieved March 4, 2005, from http://www.epa.gov/epaoswer/non-hw/recycle/jtr/comm/paper.htm 